\title{
Recomendaciones para el manejo en niños de las neumonías adquiridas en la comunidad
}

\section{Recommendations for treatment of community-acquired pneumonia in children}

Palabras claves: Neumonía adquirida en la comunidad; pediatría, etiología; tratamiento.

Key word: Community acquired pneumonia; pediatrics, etiology; treatment.

\section{Definición}

La neumonía adquirida en la comunidad (NAC) se define como un proceso inflamatorio agudo del parénquima pulmonar, de origen infeccioso, que se inicia fuera del ambiente hospitalario.

El tratamiento de la NAC en niños es empírico, ya que la mayoría de las veces no se cuenta con una etiología específica y, por lo tanto, el manejo apropiado de esta patología debe basarse en el uso racional de antimicrobianos y en el conocimiento de los siguientes aspectos:

- Criterios clínicos y de laboratorio de neumonía bacteriana.

- Etiología más frecuente por edad.

- Rol de agentes etiológicos más frecuentes según la epidemiología local.

- Resistencia antimicrobiana in vitro y su correlación in vivo.

- Conceptos básicos de farmacocinética y farmacodinamia de los antimicrobianos.

\section{Etiología}

El conocimiento de la etiología de la NAC en niños se basa en un número limitado de estudios prospectivos, los que han identificado microorganismos específicos en 40 a $80 \%$ de los $\operatorname{casos}^{1-4}$. Estos resultados están influenciados por una variedad de factores como: edad, lugar geográfico, severidad de la enfermedad (pacientes ambulatorios u hospitalizados), criterios de hospitalización, estación del año, estado de inmunización
(H. influenzae b), etc. En la práctica clínica, sin embargo, a sólo menos de un tercio de los casos se les puede documentar una etiología específica. En los Gráficos 1 y 2 y en la Tabla 1 se muestra la frecuencia de agentes etiológicos encontrados en estudios realizados en pacientes ambulatorios y hospitalizados y según edad.

En resumen, la etiología viral es la más frecuente en las NACs en niños bajo 2 años de edad y Streptococcus pneumoniae es la principal causa de neumonía bacteriana en niños a toda edad. Con menos frecuencia se encuentran $H$. influenzae (incluyendo cepas no tipificables), Staphylococcus aureus, Streptococus pyogenes y Moraxella catarrhalis. Patógenos atípicos como Mycoplasma pneumoniae y Chlamydia pneumoniae aumentan su incidencia a partir de los 5 años de edad ${ }^{5,6}$.

\section{Criterios clínicos de neumonía bacteriana}

El diagnóstico de NAC en niños se basa principalmente en síntomas y signos presentes en la historia clínica y en el examen físico: fiebre alta $>38,5^{\circ} \mathrm{C}$, tos, taquipnea (bajo 1 año de edad: más de 50 respiraciones por minuto y sobre 1 año: más de 40 respiraciones por minuto), compromiso variable del estado general, signos de dificultad respiratoria y semiología de consolidación pulmonar. La radiografía de tórax es un examen complementario y sirve para confirmar el diagnóstico, determinar el patrón radiológico (intersticial o relleno alveolar) y detectar complicaciones (efusión pleural, atelec- 
tasias, etc). Síntomas como fiebre alta mayor de $40^{\circ} \mathrm{C}$ con inicio brusco, calofríos, puntada de costado, dolor abdominal o evidencia de efusión pleural, orientan clínicamente al diagnóstico de neumonía neumocóccica.

Los exámenes generales tienen poca utilidad en diferenciar neumonía viral de bacteriana. Un estudio reciente efectuado en 254 pacientes hospitalizados, dirigido a establecer la etiología de la NAC según edad del paciente (Tabla 2), permitió objetivar la baja sensibilidad y especificidad del recuento de leucocitos, VHS, PCR y patrón radiológico ${ }^{7}$.

\section{Diagnóstico microbiológico}

- Neumonía viral: Se basa en técnicas de inmunodiagnóstico (inmunofluorescencia o EIA) y aislamiento viral. En general son técnicas con buena sensibilidad y especificidad (VRS, FLU, paraFLU) a excepción de IFD para ADV que tiene una sensibilidad de $\sim 50 \%$.

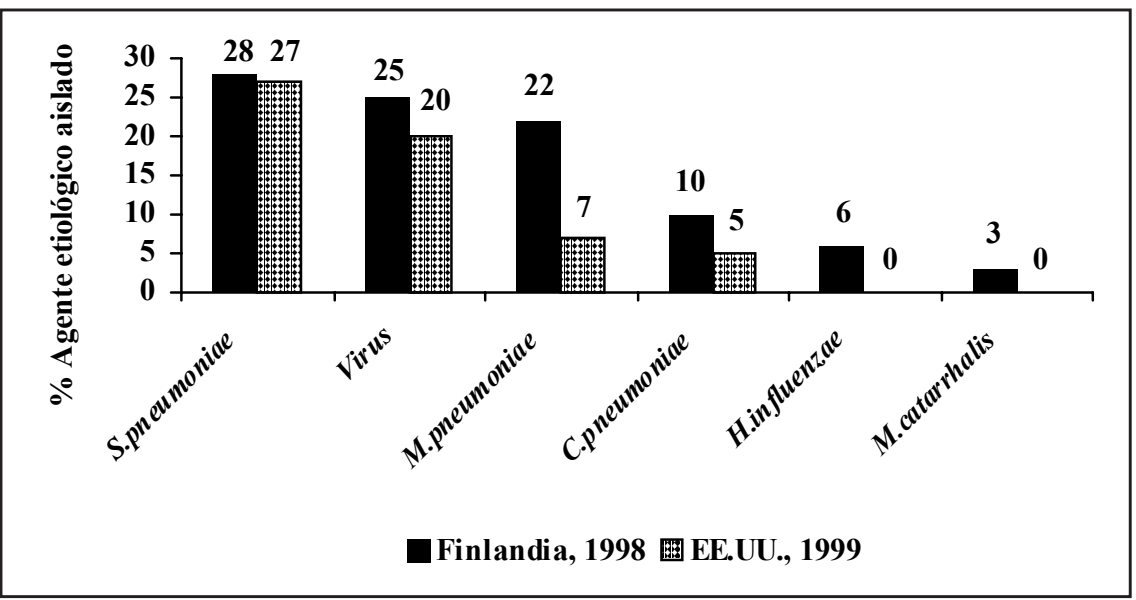

Gráfico 1. Etiología específica de NAC en pacientes ambulatorios (Refs 1,2).

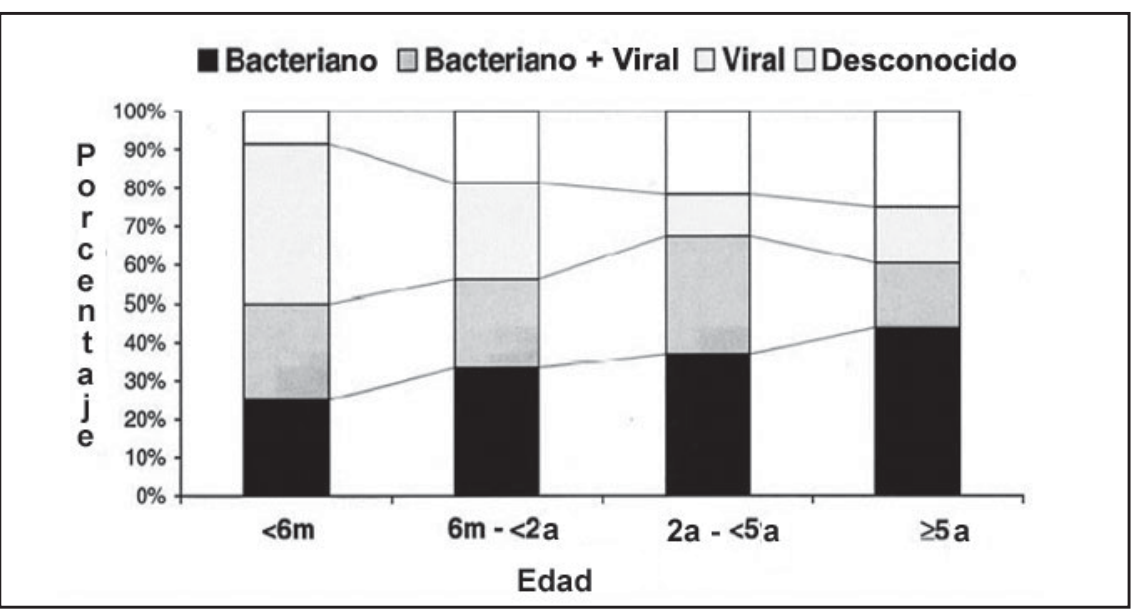

Gráfico 2. Distribución de patógenos asociados a NAC, estratificados por edad (Ref 4).

Tabla 1. Etiología de NAC en 254 pacientes hospitalizados

\begin{tabular}{lccccc}
\hline Edad & $\mathbf{n}$ & $\begin{array}{c}\text { Bacteriana } \\
\mathbf{\%}\end{array}$ & $\begin{array}{c}\text { Viral } \\
\mathbf{\%}\end{array}$ & $\begin{array}{c}\text { Mixta } \\
\mathbf{\%}\end{array}$ & $\begin{array}{c}\text { \% con detección } \\
\text { etiológica }\end{array}$ \\
\hline$<2$ años & 108 & 47 & 80 & 34 & 93 \\
$2-5$ años & 84 & 56 & 58 & 33 & 81 \\
$>5$ años & 62 & 58 & 37 & 19 & 76 \\
\hline
\end{tabular}

(Reproducido de ref 3) 
Tabla 2. Exámenes para diferenciar neumonía bacteriana de las de etiología viral

\begin{tabular}{lccc}
\hline \multicolumn{2}{c}{ Examen } & Sensibilidad & Especificidad \\
\hline \multirow{2}{*}{ Rx tórax } & $<2$ años & 0,38 & 0,40 \\
& $>2$ años & 0,62 & 0,60 \\
Leucocitos & $>15.000 / \mathrm{mm}^{3}$ & 0,48 & 0,53 \\
VHS & $>30 \mathrm{~mm} / \mathrm{h}$ & 0,66 & 0,40 \\
PCR & $>40 \mathrm{mg} / \mathrm{L}$ & 0,66 & 0,53 \\
& $>80 \mathrm{mg} / \mathrm{L}$ & 0,52 & 0,72 \\
& $>120 \mathrm{mg} / \mathrm{L}$ & 0,36 & 0,85 \\
\hline
\end{tabular}

(Adaptado de ref 7)

- Neumonía bacteriana:

- Hemocultivos: de bajo rendimiento, menos del $10 \%$.

- Punción pleural con tinción de Gram y cultivo de líquido pleural: rendimiento entre 20 y $30 \%$.

- Cultivo de expectoración: método no validado en niños y muestra de difícil obtención en niños pequeños.

- Detección de antígenos bacterianos (S. pneumoniae, Hib) en sangre, orina o líquido pleural por técnicas de látex o EIA. En general tienen baja sensibilidad y en niños además existen falsos positivos por colonización nasofaríngea o inmunizaciones recientes.

- Métodos invasores: lavado broncoalveolar y biopsia pulmonar, de buen rendimiento pero de uso inhabitual por riesgos inherentes al procedimiento.

\section{Rol de Streptococcus pneumoniae en NAC}

Por ser la causa más frecuente de NAC bacteriana en niños, el tratamiento empírico inicial debe cubrir siempre esta etiología; sin embargo, existe una creciente preocupación por la aparición de cepas resistentes a penicilina que podrían influir en un mal resultado clínico al utilizar este antimicrobiano u otro del mismo grupo.

La resistencia de $S$. pneumoniae se produce por mutaciones en el sitio de acción de la penicilina, específicamente por una disminución de la afinidad de las proteínas de unión a penicilina (PBPs) por el $\beta$-lactámico. Estos genes de resistencia son resultado de un mecanismo de transformación, mediante la adquisición de ADN foráneo desde especies resistentes como Streptococcus del grupo viridans. Teóricamente, por lo tanto, al no haber destrucción del antimicrobiano por enzimas, esta disminución de afinidad podría contrarestarse con aumentar las dosis de penicilina o con el uso de $\beta$-lactámicos más activos como cefalosporinas de $3^{\circ}$ generación.
Está demostrada la asociación entre tener una infección invasora por S. pneumoniae resistente a antimicrobianos y ciertos factores de riesgo tales como:

- Edad menor de 5 años, especialmente menos de 2 años.

- Uso previo de antimicrobianos (un mes antes).

- Tipo de infección, siendo la neumonía de mayor riesgo.

- Asistencia a guarderías infantiles ${ }^{8}$.

En Chile, un estudio realizado por R. Lagos investigó la susceptibilidad antimicrobiana de 424 cepas de $S$. pneumoniae, 118 de las cuales correspondían a casos de neumonía o pleuroneumonía; en ellas se detectó una CIM $>2 \mu \mathrm{g} / \mathrm{ml}$ (criterio de resistencia in vitro) a penicilina en $18 \%$ y a cefotaxima en 13,5\%. El porcentaje de cepas resistentes fue mayor en pacientes hospitalizados (25 y $18 \%$ respectivamente) $)^{9}$.

A pesar que estas cifras pueden parecer alarmantes, existe ya abundante evidencia en la literatura sobre la buena respuesta clínica a los $\beta$ lactámicos en neumonías causadas por cepas resistentes in vitro, lo que demuestra una falta de correlación entre ella y el resultado clínico. Por esta razón, diversos expertos han propuesto recientemente elevar los puntos de corte de susceptibilidad a penicilina en infecciones invasoras por $S$. pneumoniae fuera del SNC, definiendo resistencia alta a cepas con CIM $>4 \mu \mathrm{g} / \mathrm{ml}^{10-11}$. Tabla 3 .

\section{Elección del $\beta$-lactámico}

Los $\beta$-lactámicos son antimicrobianos tiempo dependiente, es decir, su eficacia clínica- bacteriológica está determinada por el tiempo en que la concentración plasmática se encuentra por sobre la CIM (T > CIM). En el caso específico de los $\beta$-lactámicos éste corresponde al 40-50\% del intervalo entre dosis ${ }^{12}$ (Gráficos 3 y 4 ).

En un estudio reciente realizado en Uruguay se 
Tabla 3. Nuevos valores de corte propuestos para interpretar susceptibilidad de $S$. pneumoniae en infecciones fuera del $\mathrm{SNC}^{*}$.

\begin{tabular}{lccc}
\hline Antimicrobiano & Susceptible $(\boldsymbol{\mu g} / \mathbf{m l})$ & Intermedio $(\boldsymbol{\mu g} / \mathbf{m l})$ & Resistente $(\boldsymbol{\mu g} / \mathbf{m l})$ \\
\hline Penicilina & $<1$ & 2 & $>4$ \\
Amoxicilina & $<2$ & 4 & $>8$ \\
Cefotaxima & $<1$ & 2 & $>4$ \\
\hline
\end{tabular}

Ref. $10 *$ No aceptados aún por la NCCLS.

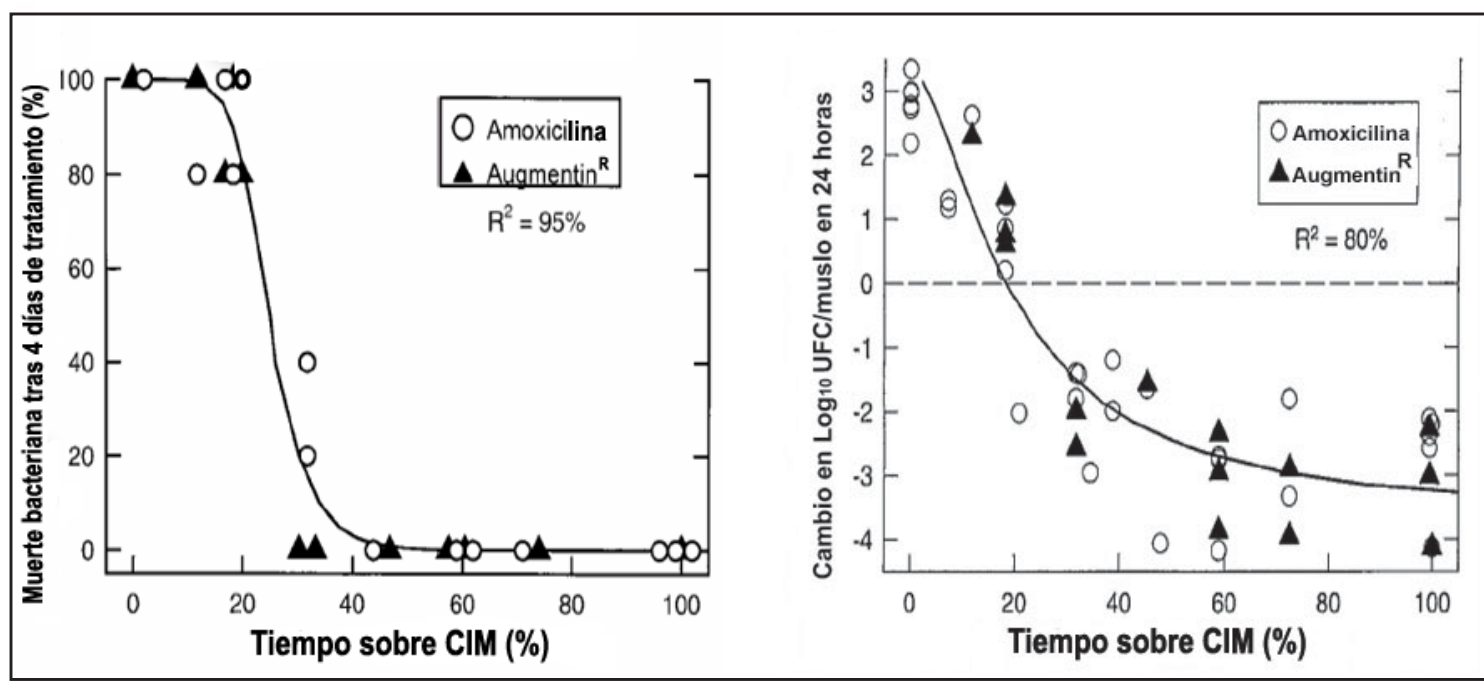

Gráficos 3 y 4. Curva de mortalidad y multiplicación bacteriana versus tiempo sobre la CIM (40-50\%) de amoxicilina y amoxicilina/ác. clavulánico (Ref 12).

midieron las concentraciones de ampicilina y penicilina $\mathrm{G}$, en suero y líquido pleural en 30 niños con neumonía neumocóccica tratados con dosis de $400 \mathrm{mg} / \mathrm{kg} /$ día y $200.000 \mathrm{UI} / \mathrm{kg} /$ día respectivamente. Ambos fármacos alcanzaron concentraciones máximas de $4 \mu \mathrm{g} / \mathrm{ml}$, con ampicilina se mantuvieron concentraciones mayores que con penicilina a las $3 \mathrm{hrs}$ y con un T > CIM de 75\% en la mayoría de las cepas. Todos los pacientes tuvieron buena evolución clínica ${ }^{13}$.

Las cefalosporinas de $3^{\circ}$ generación también alcanzan altas concentraciones plasmáticas, con un T > CIM del 40- 50\% del intervalo.

Las cefalosporinas de $2^{\circ}$ generación (cefuroxima), de $3^{\circ}$ generación orales (cefixima) y los macrólidos no han demostrado tener buena actividad in vitro sobre $S$. pneumoniae resistente ni tampoco han tenido buenos resultados clínicos por lo que no representan una buena alternativa en cepas de $S$. pneumoniae resistentes, escenario donde amoxicilina presenta las mayores ventajas, ya que posee una mejor acción intrínseca contra $S$. pneumoniae y con CIM 1 a 2 diluciones menores que penicilina ${ }^{12}$.
La frecuencia habitual de dosificación de amoxicilina es de 3 veces al día; sin embargo, estudios farmacocinéticos validan su uso 2 veces al día cuando se prescribe en dosis de 60 a 80 $\mathrm{mg} / \mathrm{kg} / \mathrm{día}^{14}$.

En cuanto a la duración de la terapia en NAC, no hay estudios controlados de tratamientos abreviados con $\beta$-lactámicos por lo que se mantiene la recomendación de 7 a 10 días.

\section{Importancia de Haemophilus influenzae}

Actualmente, ha disminuido notablemente la importancia de $H$. influenzae serotipo b como causa de infección bacteriana invasora en niños desde la introducción de la vacuna, en Chile en el año 1996. La tasa nacional actual es de 2,5 por 100.000 habitantes, notificándose el año 2003, 36 casos de infección invasora en todo el país. Un estudio de evaluación postlicencia de la vacuna en Chile demostró una efectividad de $80 \%$ en la prevención de neumonía bacteriémica y empiemas causados por $H$. influenzae b en niños ${ }^{15}$.

Sin embargo, Haemophilus influenzae serotipos no b y cepas no tipificables siguen presen- 
tes como causa de NAC en niños, variando su frecuencia entre 6 y $16 \%$ en distintos estudios ${ }^{1-4}$. El diagnóstico de cepas no tipificables se basa principalmente en técnicas serológicas, realizadas con fines epidemiológicos, necesitándose demostrar seroconversión con muestras seriadas, lo que no es de utilidad en la práctica clínica. Por este motivo, es difícil conocer la real incidencia de serotipos de $H$. influenzae no contenidos en la vacuna como causa de NAC. Debido a que $H$. influenzae es más frecuente en niños bajo 5 años de edad, debiera cubrirse esta etiología principalmente en este grupo etario.

\section{Importancia de Mycoplasma pneumoniae}

Su mayor incidencia es en la edad escolar. El cuadro clínico se caracteriza por la presencia de tos prolongada que puede acompañarse de cefalea, mialgias y odinofagia, signos de obstrucción bronquial e infiltrado pulmonar intersticial. $\mathrm{Su}$ diagnóstico es principalmente clínico y puede apoyarse con serología específica (IgM).

M. pneumoniae es susceptible a los mácrolidos; sin embargo, no existe evidencia de su utilidad en las formas leves de la enfermedad y sólo mostraría beneficios en neumonías graves con consolidación y efusión pleural.

Los nuevos macrólidos alcanzan excelentes concentraciones en pulmón, macrófagos alveolares y líquido pleural y además presentan una vida media prolongada que permite distanciar su dosificación a una o dos veces al día ${ }^{14}$. Sin embargo, por la creciente resistencia de $S$. pneumoniae a macrólidos antes comentada, su indicación debe restringirse sólo a neumonías con alta presunción de ser causada por M. pneumoniae.

\section{Recomendaciones terapéuticas}

\section{Neumonía en paciente ambulatorio:}

- Amoxicilina $50 \mathrm{mg} / \mathrm{kg} / \mathrm{día}$ (subir dosis a 75-80 $\mathrm{mg} / \mathrm{kg} /$ día cuando existe alta sospecha de $S$. pneumoniae resistente (factores de riesgo o por realidad epidemiológica local), o frente a fracaso de tratamiento con dosis habituales. Plazo mínimo: 7 días.

- Escolar con sospecha o infección documentada por M. pneumoniae: eritromicina $50 \mathrm{mg} /$ $\mathrm{kg} /$ día o claritromicina $15 \mathrm{mg} / \mathrm{kg} /$ día durante 10 a 14 días.

\section{Neumonía en paciente hospitalizado:}

- Menor de 5 años: ampicilina 100-200 mg/kg/ día IV c/6 hrs durante 7 a 10 días.
- Escolar con neumonía lobar: penicilina G 100$200.000 \mathrm{U} / \mathrm{kg} /$ día c/6 hrs durante 7 a 10 días.

- Cambiar a tratamiento oral (amoxicilina) cuando haya buena tolerancia digestiva.

- En caso de fracaso terapéutico (persistencia de fiebre $>48$ horas): cefalosporinas de $3^{\circ}$ generación: cefotaxima $100 \mathrm{mg} / \mathrm{kg} /$ día c $/ 6 \mathrm{hrs}$ o ceftriaxona $50 \mathrm{mg} / \mathrm{kg} / \mathrm{día}$ una vez al día, durante 7 a 10 días.

- Supuración pleuropulmonar: considere la adición de cloxacilina $100 \mathrm{mg} / \mathrm{kg} /$ día.

\section{Bibliografía}

1.- Heiskanen-Kosma T, Korppi M, Jokinen C, Kurki S, Heiskanen L, Juvonen H, et al. Etiology of childhood pneumonia serologic results of a prospective population based study. Pediatr Infect Dis J 1998; 17: 986-91.

2.- Wubbel L, Muniz L, Ahmed A, Trujillo M, Carubelli C, McCoig C, et al. Etiology and treatment of community-acquired pneumonia in ambulatory children. Pediatr Infect Dis J 1999; 18: 98-104.

3.- Juven T, Mertsola J, Waris M, Leinonen M, Meurman $\mathrm{O}$, Roivainen M, et al. Etiology of community-acquired pneumonia in 254 hospitalized children. Pediatr Infect Dis J 2000; 19: 293-8.

4.- Michelow I C, Olsen K, Lozano J, Rollins N K, Duffy $\mathrm{L}$ B, Ziegler $\mathrm{T}$ et al. Epidemiology and clinical characteristics of community- acquired pneumonia in hospitalized children. Pediatrics 2004; 113: 701-7.

5.- McCracken Jr G. Etiology and treatment of pneumonia. Pediatr Infect Dis J 2000; 19: 373-7.

6.- Mc Cracken Jr G. Diagnosis and management of pneumonia in children. Pediatr Infect Dis J 2000; 19 : 924-8.

7.- Virkki R, Juven T, Rikalainen H, Svedstrom E, Mertsola J, Ruuskanen O. Differentiation of bacterial and viral pneumonia in children. Thorax 2002; 57: 438-41.

8.- Consenso de S. pneumoniae resistente. XX Congreso Chileno de Infectología, La Serena 2003 (no publicado).

9.- Lagos R, Muñoz A, Valenzuela M T, Heitmann I, Levine M M. Population-based surveillance for hospitalized and ambulatory pediatric invasive pneumococcal disease in Santiago, Chile. Pediatr Infect Dis J 2002; 21: 1115-23.

10.- Heffelfinger J D, Dowell S F, Jorgensen J H, Klugman K P, Mabry L R, Musher D M et al. Management of community-acquired pneumonia in the era of pneumococcal reistance: a report from the DrugResistant Streptococcus pneumoniae therapeutic Working Group. Arch Intern Med 2000; 160: 1399408.

11.- Musher D M, Bartlett J G, Doern G V. A fresh look at the definition of susceptibility of Streptococcus pneumoniae to beta- lactam antibiotics. Arch Intern Med 2001; 161: 2538-44.

12.- Andes D, Craig W. In vivo activities of amoxicillin and amoxicillin-clavulanate against Streptococcus pneumoniae: Application to breakpoint determinations. Antimicrobial Agents Chemother 1998; 42: 2375-9. 
13.- Giachetto G, Pirez M C, Nanni L, Martínez A, Montano A, Algorta G, et al. Ampicillin and penicillin concentration in serum and pleural fluid of hospitalized children with community-acquired pnemonia. Pediatr Infect Dis J 2004; 23: 625-9.

14.- Fonseca W, Hoppu K, Rey L C, Amaral J, Qazi S. Comparing pharmacokinetics of amoxicillin given twice or three times per day to children older than 3 months with pneumonia. Antimicrobial Agents Chemother 2003; 47: 997-1001.

15.- Lagos R, Levine O S, Avendano A, Horwitz I, Levine M M. The introduction of routine Haemophilus influenzae type $\mathrm{b}$ conjugate vaccine in Chile: a framework for evaluation new vaccines in newly industrializing countries. Pediatr Infect Dis J 1998; 17 (9 Suppl) S 139-48.

Correspondencia a:

Paulina Coria de la $\mathrm{H}$.

paulina.coria@mi.cl 